\title{
PENGARUH KOMITMEN ORGANISASI DAN KEPUASAN KERJA TERHADAP ORGANIZATIONAL CITIZENSHIP BEHAVIORS (OCB) (Studi Kasus Yapis Di Tanah Papua Cabang Kabupaten Jayawijaya)
}

\author{
Soltan Takdir ${ }^{1)}$, Muhammad Ali ${ }^{2)}$ \\ Email : ${ }^{1)}$ Suletakdir1983@gmail.com, ${ }^{2}$ Muhammadali_stisip@gmail.com \\ ${ }^{1)}$ Administrasi Bisnis, Universitas Amal Ilmiah Yapis Wamena, ${ }^{2)}$ Administrasi Publik, Universitas \\ Amal Ilmiah Yapis Wamena
}

\begin{abstract}
Abstrak
Penelitian ini bertujuan menganalisis pengaruh komitmen organisasi dan kepuasan kerja terhadap Organizational Citizenship Behaviors (OCB). metode penelitian yang digunakan yaitu metode kuantitatif asosiatif. Adapun populasi pada penelitian sebanyak 191 karyawan, Yapis di Tanah Papua Cabang Kabupaten Jayawijaya sebagai yayasan yang menangani Dunia Pendidikan di Pegunungan Tengah Papua. Penentuan jumlah sampel menggunakan teknik purposive sampling yaitu dilakukan dengan menggunakan metode Judgment Sampling sehingga diperoleh 115 karyawan sebagai sampel penelitian. Metode analisis yang digunakan yaitu metode analsisi regresi linier berganda. Hasil penelitian menunjukkan bahwa komitmen organisasi secara positif tetapi tidak signifikan mempengaruhi $O C B$, sedangkan Kepuasan Kerja secara positif dan signifikan mempengaruhi OCB, secara bersamaan baik Komitmen Organisasi dan Kepuasan Kerja secara positif dan signifikan mempengaruhi OCB karyawan.
\end{abstract}

Kata Kunci: Komitmen Organisasi, Kepuasan Kerja, Organizational Citizenship Behaviors.

\begin{abstract}
This study aimed to analyze the effect of organizational commitment and job satisfaction on Organizational Citizenship Behaviors (OCB). The research method used is an associative quantitative method. The study population was 191 Yapis employees in Tanah Papua Jayawijaya Branch as a foundation that handles the World of Education in the Central Papua Mountains. Determining the number of samples using a purposive sampling technique is done using the Judgment Sampling method so that 115 employees are obtained as a research sample. The analytical method used is the multiple linear regression analysis methods. The results showed that organizational commitment positively but did not significantly affect OCB, while Job Satisfaction positively and significantly affected OCB. Simultaneously, both Organizational Commitment and Job Satisfaction positively and affected OCB employees considerably.
\end{abstract}

Keywords: Organizational Commitment, Job Satisfaction, Organizational Citizenship Behaviors.

\section{PENDAHULUAN}

Setiap organisasi yang ada akan berusaha dengan semaksimal mungkin untuk mempertahankan keberadaannya menuju tujuan yang ingin dicapai dimana lingkungan organisasi bekerja dalam lingkungan yang dinamis, ambigu dan variabel. Dalam usaha untuk bertahan ditengah perubahan lingkungan yang terjadi akan memaksa organisasi untuk selalu beradaptasi demi kelangsungan hidup organisasi dan menjadi dinamika kehidupan organisasi sehari-hari (Bolognese dalam Prihatsanti \& Dewi, 2010; Hadjali \& Salimi, 2012; Haedar, Saharuddin, \& H, 2015; Sayuti \& Sammang, 2018).

Efektifitas dan kinerja tim dalam organisasi didapatkan melalui kemampuan anggota dalam tim kerja tersebut, pegawai tidak hanya harus melakukan sesuai dengan tuntutan tugas yang terkandung dalam tugas pokoknya atau biasa disebut in - role, namun pegawai disarankan memiliki inisiatif untuk melakukan pekerjaan tambahan diluar tuntutan tugasnya atau biasa disebut extra role. Perilaku extra role dalam organisasi tersebut biasa dikenal dengan istilah Organizational Citizenship Behaviors (OCB) (Ogoz dalam Fitriastuti, 2013; Er Hamza, 2015). Konsep Perilaku Citizenship Organisasi (OCB) pertama kali secara resmi diartikulasikan oleh Chester Barnard sebagai kesediaan individu dalam organisasi untuk bekerja sama. Kemudian Katz (1964) membedakan konsep OCB sebagai "inovatif dan perilaku spontanitas " yang bertentangan dengan kinerja peran yang lebih wajib (Hadjali \& Salimi, 2012; Harper, 2015). 
Menurut Organ et.al (Islam, Khan, Ahmad, \& Ahmed, 2014) OCB adalah perilaku non-organisasi yang tidak dapat diamati dengan sistem reward atau hukuman. OCB juga dapat meningkatkan efisiensi suatu organisasi dengan cara menghemat berbagai jenis sumber daya yang ada untuk tujuan yang lebih produktif (Syahril \& Widyarini, 2007; Polat, 2009). Menurut Organ (Hidayat, 2014) Organizational Citizenship Behavior (OCB) mempunyai lima indikator utama yang masing - masing bersifat unik yaitu: altruism, courtesy,sportsmanship, conscientiousness, civic virtue.

Salah satu faktor yang mempengaruhi OCB adalah komitmen organisasi. Menurut Sopiah (Utama \& Wibawa, 2016) menyatakan bahwa komitmen organisasi merupakan suatu keinginan yang dimiliki oleh anggota organisasi untuk tetap bertahan dalam organisasi serta berusaha keras untuk mewujudkan tujuan organisasi. Penelitian yang menunjukkan adanya pengaruh komitmen organisasi terhadap OCB diantaranya (Utama \& Wibawa, 2016; Dewi \& Suwandana, 2016; Prabandewi \& Indrawati, 2016; Purba \& Seniati, 2004; Ristiana, 2013; Zeinabadi \& Salehi, 2011), Akan tetapi, terdapat pula penelitian yang menunjukkan bahwa komitmen organisasi tidak berpengaruh siginifikan terhadap OCB diantaranya (Arum, Lina, \& Herlina, 2013), Brahmasari (2008) dalam (Rini, Rusdarti, \& Suparjo, 2013). Menurut Meyer dan Allen dalam Puspitawati \& Riana (2014) merumuskan tiga dimensi komitmen organisasional, yaitu Komitmen afektif (affective commitment), Komitmen berkelanjutan (continuance commitment), Komitmen normatif (normative commitment).

Selain faktor komitmen organisasi, kepuasan kerja sebagai salah satu faktor yang mempengaruhi OCB. Menurut Luthans dalam Puspitawati \& Riana (2014) menyatakan bahwa kepuasan kerja adalah hasil dari persepsi karyawan mengenai seberapa baik pekerjaan mereka memberikan hal yang dianggap penting. Penelitian yang menunjukkan adanya pengaruh kepuasan kerja terhadap OCB diantaranya (Arum et al., 2013; Islam et al., 2014; Rini et al., 2013; Ristiana, 2013; Zeinabadi \& Salehi, 2011). Menurut Luthans dalam Widyanto, Lau, Kartika, Perhotelan, \& Petra (2013) Ada lima dimensi kepuasan kerja diantaranya Job it self (Pekerjaan itu Sendiri),Supervision (Pengawasan), Pay (Imbalan), Promotion (Kesempatan Kerja), Co-Workers (Rekan Kerja).

Yayasan Pendidikan Islam (Yapis) di Tanah Papua Cabang Kabupaten Jayawijaya bergerak dibidang pendidikan sejak tahun 1976 Hingga saat ini memiliki 5 Unit Pelaksana Teknis (UPT) mulai dari tingkatan Sekolah Dasar (SD) hingga pada tingkatan Perguruan Tinggi. Sebagai salah satu Yayasan Pendidikan di Kabupaten Jayawijaya, tentulah memegang amanah penting dalam meningkatkan tingkat pendidikan masyarakat Kabupaten Jayawijaya membutuhkan pegawai baik tenaga pendidik (guru dan dosen) serta tenaga kependidikan (staf dan operator) yang tidak hanya menjalankan tugas pokoknya dalam menuangkan sejumlah bahan pelajaran, membimbing dan membina agar menjadi anak didik yang cerdas dan berakhlak mulia ditengah keterbatasan yang dimiliki oleh pegawai yang ada. Tetapi terdapat pula kegiatan lain yang dijalankan diantaranya kepanitiaan kegiatan sekolah dan yayasan, menghadapi kenakalan remaja yang seringkali kegiatan tersebut dilaksanakan diluar jam kerja dengan kondisi alam yang berbeda dengan kota lainnya. Atas dasar kenyataan ini, maka peneliti merasa tertarik untuk melakukan penelitian dengan judul Pengaruh Komitmen Organisasi dan Kepuasan Kerja Terhadap Organizational Citizenship Behaviors (OCB).

Berdasarkan uraian latar belakang diatas maka rumusan masalah dalam penelitian ini adalah 1) Apakah Komitmen Organisasi berpengaruh signifikan terhadap Organizational Citizenship Behaviors (OCB)? 2) Apakah Kepuasan Kerja berpengaruh signifikan terhadap Organizational Citizenship Behaviors (OCB)? 3) Apakah Komitmen Organisasi dan Kepuasan Kerja berpengaruh signifikan terhadap Organizational Citizenship Behaviors (OCB)?

\section{METODE PENELITIAN}

\section{Jenis Penelitian dan Lokasi Penelitian}

Jenis Penelitian yang dengan metode penelitian kuantitatif jenis asosiatif. Sehingga dalam penelitian ini menjelaskan hubungan sebab akibat (kausal) antara 2 (dua) variabel bebas (independent variable) yaitu variabel Komitmen Organisasi $\left(\mathrm{X}_{1}\right)$ dengan indikator Komitmen afektif (affective commitment), Komitmen berkelanjutan (continuance commitment), Komitmen normatif (normative commitment). Variabel Kepuasan Kerja $\left(\mathrm{X}_{2}\right)$ dengan indikator Pay (Imbalan), Co-Workers (Rekan Kerja), Supervision (Pengawasan), Job it self (Pekerjaan itu Sendiri), terhadap 1 (satu) variabel terikat (dependent variable) yaitu OCB (Y) dengan indikator altruism, courtesy, sportsmanship, conscientiousness, civic virtue. Penelitian dilaksanakan pada Yayasan Pendidikan Islam di Tanah Papua Cabang Kabupaten Jayawijaya.

\section{Teknik Pengumpulan Data}

Teknik pengumpulan data dilaksanakan dengan berbagai cara diantaranya dengan cara mengamati langsung dan pencatatan secara sistematis terhadap obyek peneltian. Daftar Pertanyaan (kuesioner), dan Dokumentasi dilakukan dengan cara pencatatan dari sejumlah dokumen (arsip) atau bukti - bukti lain yang terdapat pada lokasi penelitian yang dilaksanakan yang berhubungan dengan masalah yang diteliti. Instrument penelitian yang digunakan adalah dengan menggunakan skala likert dalam bentuk kuesioner pernyataan dengan rincian sangat setuju skor 5 , setuju skor 4 , ragu - ragu skor 3, tidak setuju skor 2 dan sangat tidak setuju skor 1. Dalam menguji kualitas instrument penelitian dilakukan uji validitas dan realibilitas

\section{Populasi dan Sampel}

Populasi merupakan keseluruhan dari objek atau subjek ataupun individu pada suatu wilayah yang akan diteliti (Hamid \& Patra, 2019). Adapun populasi yang digunakan pada penelitian ini yaitu sebanyak 191 
pegawai baik tenaga pendidik (Guru dan Dosen) maupun tenaga kependidikan yang tersebar pada 5 UPT (Unit Pelaksana Teknis) diantaranya STISIP Amal Ilmiah Yapis Wamena, SMK Sidratul Muntaha Yapis Wamena, SMP Nurul Haq Yapis Wamena, SD Attahiriyah Yapis Wamena dan MI Merasugun Asso Walesi. Sampel adalah kumpulan atau bagian dari populasi yang terpilih dengan prosedur tertentu yang bisa merepresentasikan populasi (Hamid \& Patra, 2019). Penentuan sampel pada penelitian ini menggunakan teknik purposive sampling dengan metode Judgment Sampling dengan kriteria Pegawai pada Yayasan Pendidikan Islam di Tanah Papua cabang Kabupaten Jayawijaya dengan masa kerja minimal 1 (satu) tahun serta yang tidak berada dalam level manajerial (ketua Sekolah Tinggi, Kepala Sekolah, Wakil-Wakil) diasumsikan memiliki pemahaman perilaku OCB sebagai hasil dari komitmen organisasi dan kepuasa kerja sehingga di dapatkan sebanyak 115 pegawai.

\section{HASIL DAN PEMBAHASAN}

\section{Hasil Uji Validitas dan Realibilitas}

Dalam uji validitas ini dilakukan pengujian atas butirbutir pertanyaan pada kuisioner dengan jalan menghitung koefisien korelasi Pearson dari tiap-tiap pertanyaan dengan skor total yang diperoleh. Selanjutnya dibandingkan dengan angka $r$ tabel dengan derajat kebebasan (0.05). Sehingga penjabaran tiap tiap butir pernyataan pada kuesioner pada Variabel Organizational Citizenship Behaviors $\left(\mathrm{Y}_{1}\right)$ dengan 20 item pernyataan nilai $r_{\text {hitung }}$ berada pada rentang nilai 0,200 hingga 0,627. Pada variabel Komitmen Organisasi $\left(\mathrm{X}_{1}\right)$ dengan 21 item pernyataan nilai $\mathrm{r}_{\text {hitung }}$ berada pada rentang nilai 0.250 hingga 0.625 . sedangkan pada variabel Kepuasan Kerja $\left(\mathrm{X}_{2}\right)$ dengan 16 item pernyataan nilai $r_{\text {hitung }}$ berada pada rentang nilai 0.485 hingga 0.668 . Sehingga nilai $r_{\text {hitung }}$ lebih besar dari nilai $\mathrm{r}_{\text {tabel }}(0.185)$ dan dapat disimpulkan seluruh item pernyataan pada tiap variabel dinyatakan valid.

Pengujian realibilitas dengan menggunakan nilai cronbach alpha, suatu variabel maupun konstruk dikatakan reliabel jika memberikan nilai croanbach's alpha $>0,60$. Berdasarkan hasil pengujian didapatkan nilai cronbach's alpha variabel Organizational Citizenship Behaviors ( $\left.\mathrm{Y}_{1}\right)$ sebesar 0.746, variabel Komitmen Organisasi $\left(\mathrm{X}_{1}\right)$ sebesar 0.797 , sedangkan variabel Kepuasan Kerja $\left(\mathrm{X}_{2}\right)$ sebesar 0.872 dimana semua nilai cronbach's alpha $>0.60$ sehingga seluruh variabel yang digunakan reliabel.

\section{Karakteristik Responden}

Berdasarkan hasil kuesioner yang telah dibagikan dapat menggambarkan berbagai kondisi yang ada pada lokasi penelitian diantaranya dari segi umur dimana dominan responden berada pada usia $>30-35$ tahun $(32,2 \%)$, yang berusia $<25$ tahun sebesar $7 \%$, berusia $25-30$ tahun dan $>35$ - 40 tahun masing - masing sebesar 17,4 $\%$, serta yang berusia $>40$ tahun sebesar $26,1 \%$. Jika ditinjau dari segi agama dominan responden beragama islam sebesar $92,2 \%$ dan beragama Kristen protestan sebesar 7,8\%. Pada segi tingkat pendidikan responden dominan pada tingkat pendidikan sarjana sebesar 77,4\%, kemudian Magister sebesar 13,9\% SMA/SMK sebesar $8,7 \%$. Adapun pada keadaan responden berdasarkan status pegawai dominan berstatus guru negara sebesar 45,2\%, guru yayasan sebesar $25,2 \%$, pegawai yayasan sebesar $15,7 \%$, Dosen Yayasan sebesar 10,4\% dan pegawai PNS sebesar 3,5\%.

\begin{abstract}
Analisa Deskriptif
Analisis Deskriptif digunakan untuk menjelaskan variabel berdasarkan hasil dari data. Analisis yang digunakan dengan menggunakan analisa skor berdasarkan rerata emprik dan rerata hipotetik.Dalam mendeskripsikan hasil penelitian yang ada, peneliti membuat tiga kategori dengan berdasarkan nilai mean dan standar deviasi dengan rincian kategori rendah, sedang dan tinggi. Untuk menguraikan secara detail Variabel OCB berdasarkan indikator yang digunakan dengan skala kuesioner 1 - 5 dan masing - masing indikator jumlah item 4 dapat dirincikan sebagai berikut:
\end{abstract}

Tabel 2.

Data Hasil Penelitian Variabel Organizational Citizenship Behaviors Berdasarkan Indikator

\begin{tabular}{|c|c|c|c|c|c|c|c|c|c|c|}
\hline \multirow{3}{*}{ Indikator } & \multirow{3}{*}{$\mathrm{N}$} & \multicolumn{4}{|c|}{ Data Hipotetik } & \multicolumn{4}{|c|}{ Data Empirik } & \multirow{3}{*}{ Kategori } \\
\hline & & \multirow{2}{*}{ Mean } & \multicolumn{2}{|c|}{ Skor } & \multirow{2}{*}{$\mathrm{SD}$} & \multirow{2}{*}{ Mean } & \multicolumn{2}{|c|}{ Skor } & \multirow{2}{*}{ SD } & \\
\hline & & & Min & Max & & & Min & Max & & \\
\hline Altruism & 115 & 12 & 4 & 20 & 2,7 & 15,79 & 11 & 20 & 1,7 & Tinggi \\
\hline Courtesy & 115 & 12 & 4 & 20 & 2,7 & 16,56 & 12 & 20 & 1,4 & Tinggi \\
\hline Sportmanship & 115 & 12 & 4 & 20 & 2,7 & 14,26 & 9 & 19 & 1,9 & Sedang \\
\hline Conscientiousness & 115 & 12 & 4 & 20 & 2,7 & 15,72 & 12 & 20 & 1,4 & Tinggi \\
\hline Civic Virtue & 115 & 12 & 4 & 20 & 2,7 & 16,61 & 13 & 20 & 1,7 & Tinggi \\
\hline
\end{tabular}


Berdasarkan tabel 2 diketahui bahwa rerata empirik untuk pada masing - masing indikator Organizational Citizenship Behaviors lebih besar dari rerata hipotetiknya hal ini menunjukkan bahwa pegawai di Yayasan Pendidikan Islam di Tanah Papua Cabang Kabupaten Jayawijaya rata - rata memiliki perilaku berada pada kategori tinggi kecuali pada perilaku
Sportmanship berada pada kategori sedang. Untuk menguraikan secara detail Variabel Komitmen Organisasi berdasarkan indikator yang digunakan dengan skala kuesioner 1 - 5 dan masing - masing indikator jumlah item 7 dapat dirincikan sebagai berikut:

Tabel 3.

Data Hasil Penelitian Variabel Komitmen Organisasi Berdasarkan Indikator

\begin{tabular}{|c|c|c|c|c|c|c|c|c|c|c|}
\hline \multirow{3}{*}{ Indikator } & \multirow{3}{*}{$\mathrm{n}$} & \multicolumn{4}{|c|}{ Data Hipotetik } & \multicolumn{4}{|c|}{ Data Empirik } & \multirow{3}{*}{ Kategori } \\
\hline & & \multirow{2}{*}{ Mean } & \multicolumn{2}{|c|}{ Skor } & \multirow{2}{*}{ SD } & \multirow{2}{*}{ Mean } & \multicolumn{2}{|c|}{ Skor } & \multirow{2}{*}{ SD } & \\
\hline & & & Min & Max & & & Min & Max & & \\
\hline Afektif & 115 & 21 & 7 & 35 & 4,7 & 26,68 & 20 & 33 & 2,5 & Tinggi \\
\hline Continuance & 115 & 21 & 7 & 35 & 4,7 & 21,82 & 13 & 33 & 3,8 & Sedang \\
\hline Normative & 115 & 21 & 7 & 35 & 4,7 & 24,42 & 17 & 34 & 3,1 & Sedang \\
\hline
\end{tabular}

Berdasarkan tabel 3 diketahui bahwa rerata empirik untuk pada masing - masing indikatorKomitmen Organisasi lebih besar dari rerata hipotetiknya hal ini menunjukkan bahwa pegawai di Yayasan Pendidikan Islam di Tanah Papua Cabang Kabupaten Jayawijaya memiliki perilaku Komitmen Organisasi berdasarkan Afektik berada pada kategori tinggi sedangkan pada perilaku komitmen organisasi pada Continuance dan Normative berada pada kategori sedang.

Untuk menguraikan secara detail variabel kepuasan kerja berdasarkan indikator yang digunakan dengan skala kuesioner 1 - 5 dan masing - masing indikator jumlah item 7 dapat dirincikan sebagai berikut:

Tabel 4.

Data Hasil Penelitian Variabel Kepuasan Kerja berdasarkan indikator

\begin{tabular}{|c|c|c|c|c|c|c|c|c|c|c|}
\hline \multirow{3}{*}{ Indikator } & \multirow{3}{*}{$\mathrm{n}$} & \multicolumn{4}{|c|}{ Data Hipotetik } & \multicolumn{4}{|c|}{ Data Empirik } & \multirow{3}{*}{ Kategori } \\
\hline & & \multirow{2}{*}{ Mean } & \multicolumn{2}{|c|}{ Skor } & \multirow{2}{*}{ SD } & \multirow{2}{*}{ Mean } & \multicolumn{2}{|c|}{ Skor } & \multirow{2}{*}{ SD } & \\
\hline & & & Min & Max & & & Min & Max & & \\
\hline Gaji & 115 & 12 & 4 & 20 & 2,7 & 14,5 & 7 & 20 & 2,2 & Sedang \\
\hline Rekan Kerja & 115 & 12 & 4 & 20 & 2,7 & 15,53 & 11 & 20 & 1,8 & Tinggi \\
\hline Atasan & 115 & 12 & 4 & 20 & 2,7 & 15,63 & 9 & 20 & 2,0 & Tinggi \\
\hline Pekerjaan & 115 & 12 & 4 & 20 & 2,7 & 15,56 & 10 & 20 & 1,5 & Tinggi \\
\hline
\end{tabular}

Berdasarkan tabel 4 diketahui bahwa rerata empirik untuk pada masing - masing indikator Organizational Citizenship Behaviors lebih besar dari rerata hipotetiknya hal ini menunjukkan bahwa pegawai di Yayasan Pendidikan Islam di Tanah Papua Cabang Kabupaten Jayawijaya memiliki kepuasan kerja berdasarkan rekan kerja, atasan dan pekerjaan berada pada kategori tinggi sedangkan kepuasan kerja pada gaji berada pada kategori sedang.

\section{Analisis Regresi Linear Berganda}

Analisis regresi berganda digunakan mengetahui pengaruh variabel dependen (terikat) terhadap satu atau lebih variabel independen sebagai faktor prediktor dimanipulasi (dinaikturunkan nilainya). Hasil analisis regresi berganda pada variabel Komitmen Organisasi
$\left(\mathrm{X}_{1}\right)$, Kepuasan Kerja $\left(\mathrm{X}_{2}\right)$ dan Organizational Citizenship Behaviors (Y) dalam tabel berikut ini:

Tabel 5.

Hasil Analisis Regresi Linear Berganda

\begin{tabular}{|l|l|l|l|l|}
\hline $\begin{array}{l}\text { Variabel } \\
\text { Penelitian }\end{array}$ & $\begin{array}{l}\text { Koefisien } \\
\text { Regresi }\end{array}$ & Nilai t & $\begin{array}{l}\text { Korelasi } \\
\text { Parsial }\end{array}$ & Sig \\
\hline $\begin{array}{l}\text { Komitmen } \\
\text { Organisasi } \\
\left(\mathrm{X}_{1}\right)\end{array}$ & 0,071 & 0,980 & 0,231 & 0,329 \\
\hline $\begin{array}{l}\text { Kepuasan } \\
\text { Kerja }\left(\mathrm{X}_{2}\right)\end{array}$ & 0,297 & 3,296 & 0,360 & 0,001 \\
\hline Konstanta & 55,545 & \multicolumn{3}{|l|}{} \\
\hline F Hitung & 8,887 & & Sig & 0,000 \\
\hline R Square & 0,137 & & & \\
\hline
\end{tabular}


Tabel 5 menunjukkan persamaan regresi linear berganda dengan rincian sebagai berikut

$\hat{Y}=55,545+0,071 X_{1}+0,297 X_{2}+e$.

\section{Pengujian Hipotesis Parsial (Uji T)}

Hipotesis penelitian yang diajukan terdiri atas 2 bagian yaitu $\mathrm{H}_{1}=$ Komitmen Organisasi Berpengaruh secara signifikan terhadap Organizational Citizenship Behaviors (OCB) . Dan $\mathrm{H}_{2}=$ Kepuasan Kerja Berpengaruh secara signifikan terhadap Organizational Citizenship Behaviors (OCB). Dalam pengujian hipotesis tersebut menggunakan metode uji $-\mathrm{t}$ dengan cara membandingkan antara $t_{\text {tabel }}$ dan $t_{\text {hitung }}$ dari tabel 5 diatas didapatkan nilai thitung pada variabel Komitmen Organisasi sebesar 0,980 dan nilai $t_{\text {tabel }}$ pada $\alpha=0,05$ untuk uji dua pihak didapatkan sebesar 1,982 sehingga $\mathrm{t}_{\text {hitung }}(0,980)<\mathrm{t}_{\text {tabel }}(1,982)$ serta nilai sig 0,329>0,05. Dengan demikian $\mathrm{H}_{1}$ ditolak dan dapat disimpulkan Komitmen Organisasi tidak berpengaruh secara signifikan terhadap OCB. Pada variabel Kepuasan Kerja $\left(X_{2}\right)$ di dapatkan nilai thitung sebesar 3,296 dan nilai $t_{\text {tabel }}$ sebesar 1,982 sehingga $t_{\text {hitung }}(3,296)>t_{\text {tabel }}$ serta nilai sig $0,001<0,05$. Dengan demikian $\mathrm{H}_{2}$ diterima dan dapat disimpulkan kepuasan kerja berpengaruh secara signifikan terhadap OCB

\section{Pengujian Hipotesis Simultan (Uji F)}

Hipotesis penelitian yang diajukan adalah $\mathrm{H}_{3}=$ Komitmen Organisasi dan Kepuasan Kerja Berpengaruh signifikan terhadap OCB secara simultan. Dalam pengujian hipotesis secara simultan menggunakan metode uji $f$ dengan cara membandingkan nilai $f_{\text {hitung }}$ dan nilai $\mathrm{f}_{\text {tabel. }}$. Berdasarkan nilai $\mathrm{f}_{\text {hitung }}$ pada tabel 5 diatas sebesar 8,887 dan nilai $\mathrm{f}_{\text {tabel }}$ dengan $\alpha=0,05$ sebesar 3,0884 . Sehingga dapat dipahami nilai $f_{\text {hitung }}(8,887)>$ $\mathrm{f}_{\text {tabel }}(3,0884)$. Dengan demikian hipotesis $\mathrm{H}_{3}$ diterima yaitu komitmen organisasi dan kepuasan kerja berpengaruh signifikan terhadap OCB secara simultan.

\section{Koefisien Korelasi Parsial}

Korelasi parsial digunakan untuk mengetahui variabelvariabel bebas yang mempunyai pengaruh yang dominan terhadap variabel terikat. Untuk mengetahui variabel bebas yang mempunyai pengaruh yang dominan terhadap variabel terikat digunakan nilai korelasi parsial atau nilai sig yang diperoleh ( $p$ value). Nilai korelasi parsial yang paling besar atau nilai sig ( $p$ value) yang paling kecil merupakan variabel bebas yang mempunyai pengaruh yang dominan terhadap variabel terikat. Berdasarkan hasil analisis pada tabel 5 menunjukkan variabel kepuasan kerja $\left(\mathrm{X}_{2}\right)$ mempunyai pengaruh dominan terhadap Variabel Organizational Citizenship Behaviors (OCB). Hal tersebut ditunjukkan dengan nilai korelasi parsial sebesar 0,360 dan nilai sig ( $p$ value) sebesar 0,001 di mana nilai korelasi parsial yang paling besar dan nilai sig yang paling kecil dari variabel bebas lainnya (Komitmen Organisasi $\left(\mathrm{X}_{1}\right)$.

\section{Koefisien Determinasi}

Nilai koefisien determinasi dari tabel 5 diatas sebesar 0,137 hal ini menunjukkan bahwa kontribusi variabel komitmen organisasi $\left(\mathrm{X}_{1}\right)$ dan Variabel Kepuasan Kerja $\left(\mathrm{X}_{2}\right)$ pada perubahan OCB (Y) sebesar 13,7 \% sedangkan sisanya $86,3 \%$ dipengaruhi oleh variabel lain diluar dari model analisis.

\section{Pengaruh Komitmen Organisasi Terhadap Organizational Citizenship Behaviors}

Berdasarkan hasil uji - $\mathrm{t}$ Komitmen Organisasi sebesar $0,980<\mathrm{t}_{\text {tabel }}(1,982)$ serta nilai sig $0,329>0,05$. Hal ini menunjukkan komitmen organisasi berpengaruh positif tetapi tidak signifikan terhadap Organizational Citizenship Behaviors Dengan demikian dapat dipahami bahwa jika komitmen organisasi meningkat tidak mempengaruhi secara signifikan peningkatan Organizational Citizenship Behaviors di Yayasan Pendidikan Islam di Tanah Papua Cabang Kabupaten Jayawijaya. Hal tersebut diperkuat berdasarkan hasil korelasi parsial yang didapatkan $(0,231)$ yang menunjukkan hubungan antara komitmen organisasi dan OCB masih rendah. Hal ini dimungkinkan terjadi karena perilaku komitmen organisasi pegawai yang belum maksimal sehingga tidak mempengaruhi secara signifikan perilaku OCB yang dimiliki pegawai.

Jika dianalisis lebih jauh dapat kita uraikan dengan hasil perhitungan rerata empirik dan rerata hipotetik komitmen organisasional beserta perhitungan dari indikator komitmen organisasional. Rerata empirik untuk pada masing - masing indikator Organizational Citizenship Behaviors lebih besar dari rerata hipotetiknya hal ini menunjukkan bahwa pegawai di Yayasan Pendidikan Islam di Tanah Papua Cabang Kabupaten Jayawijaya rata - rata memiliki perilaku berada pada kategori tinggi kecuali pada perilaku Sportmanship berada pada kategori sedang. Rerata empirik untuk pada masing - masing indikator Komitmen Organisasi lebih besar dari rerata hipotetiknya hal ini menunjukkan bahwa pegawai di Yayasan Pendidikan Islam di Tanah Papua Cabang Kabupaten Jayawijaya memiliki perilaku Komitmen Organisasi berdasarkan Afektik berada pada kategori tinggi sedangkan pada perilaku komitmen organisasi pada Continuance dan Normative berada pada kategori sedang. Sehingga tingkat komitmen organisasi pegawai masih dalam kategori sedang bila dibandingkan dengan perilaku OCB pegawai sudah dalam kategori tinggi.

Penelitian ini juga diketahui bahwa dari ketiga faktor komitmen organisasi, didapatkan komitmen afektit pada kategori tinggi menurut Triatna (2015) pegawai yang memiliki komitmen afektif yang tinggi cenderung untuk mempertahankan dirinya dalam organisasi, peduli terhadap organisasi dan berkeinginan untuk mencurahkan usahanya atas nama organisasi. Akan tetapi hal yang berbeda didapatkan pada komitmen continuance (berkelanjutan) dan komitmen normative berada pada kategori sedang. Menurut Meyer dan Allen (Majorsy, 2007) komitmen continuance (berkelanjutan) mengacu pada kesadaran individu atas kerugian yang akan ditanggung bila meninggalkan organisasi sedangkan komitmen normative menunjukkan bagaimana individu dapat bertahan di dalam organisasi 
karena ia merasa memiliki tugas atau kewajiban moral terhadap organisasinya. Sehingga dapat dipahami bahwa komitmen continuance dan normative didasarkan dari ikatan kuat dengan organisasi yang dipengaruhi dari luar pegawai berbeda dengan komitmen afektif yang berasal dari dalam individu pegawai. Hal ini dapat kita pahami kondisi kerja pegawai yang kurang memadai baik ditinjau dari segi keamanan maupun dari factor lainnya sehingga pegawai meskipun ada keinginan untuk bertahan dalam organisasi tetapi masih memiliki perasaan tidak mewajibkan dirinya untuk bertahan hingga pensiun yang disebabkan karena faktor dliuar individu pegawai. Hasil penelitian ini mendukung beberapa penelitian terdahulu diantaranya (Arum et al., 2013) (Purba \& Seniati, 2004) .

\section{Pengaruh Kepuasan Kerja Terhadap Organizational Citizenship Behaviors}

Berdasarkan hasil uji - t kepuasan kerja sebesar 3,296 > $t_{\text {tabel }}(1,982)$ serta nilai sig $0,001<0,05$. Uji hipotesis membuktikan bahwa kepuasan kerja berpengaruh positif dan signifikan terhadap Organizational Citizenship Behaviors Dengan demikian dapat dipahami bahwa jika komitmen organisasi meningkat mempengaruhi secara signifikan peningkatan Organizational Citizenship Behaviors di Yayasan Pendidikan Islam di Tanah Papua Cabang Kabupaten Jayawijaya. Berdasarkan hasil korelasi parsial yang didapatkan $(0,360)$ yang menunjukkan hubungan antara kepuasan kerja dan OCB masih rendah. Tingkat kepuasan kerja pegawai kategori tinggi. Sehingga dapat dipahami bahwa kepuasan kerja yang dimiliki pegawai belum mampu mendorong perilaku OCB. Meskipun hasil penelitian menunjukkan kepuasan pegawai pada indikator kepuasan rekan kerja, atasan dan pekerjaan masuk dalam kategori tinggi.

Penelitian ini juga diketahui kepuasan kerja pada indikator gaji masih dalam kategori sedang. Menurut Robbins (2001) (Widyanto et al., 2013) bahwa para karyawan menginginkan sistem upah dan kebijakan promosi yang dipersepsikan sebagai adil, tidak meragukan, dan segaris dengan pengharapan mereka. Bila upah dilihat sebagai adil yang didasarkan pada tuntutan pekerjaan, tingkat ketrampilan individu, dan standar pengupahan komunitas, kemungkinan besar akan dihasilkan kepuasan. Hal tersebut dapat dipahami keadaan Wamena Sebagai ibu kota Kabupaten Jayawijaya dimana standar pengupahan yang ada jauh lebih rendah dengan harga barang yang ada. Hasil Penelitian ini mendukung beberapa penelitian terdahulu diantaranya (Arum et al., 2013; Dewi \& Suwandana, 2016; Rini et al., 2013; Ristiana, 2013; Widyanto et al., 2013)

\section{Pengaruh Komitmen Organisasi dan Kepuasan Kerja Terhadap Organizational Citizenship Behaviors}

Berdasarkan hasil Uji - f, dimana nilai $f_{\text {hitung }}$ sebesar 8,887 lebih besar dari $f_{\text {tabel }} 3,0884$. Uji Hipotesis membuktikan bahwa komitmen organisasi dan kepuasan kerja secara simultan berpengaruh positif dan signifikan terhadap OCB. Dengan demikian dapat dipahami bahwa jika komitmen organisasi dan kepuasan kerja secara simultan meningkat akan mempengaruhi secara signifikan peningkatan Organizational Citizenship Behaviors pegawai di Yayasan Pendidikan Islam di Tanah Papua Cabang Kabupaten Jayawijaya. Hasil analisis juga menunjukkan persamaan regresi linear berganda dengan rincian $\hat{Y}=55,545+0,071 X_{1}+$ $0,297 X_{2}+e$. Berdasarkan persamaan regresi tersebut dapat dijelaskan nilai OCB sebesar 55,545 satuan jika variabel Komitmen Organisasi $\left(\mathrm{X}_{1}\right)$ dan Kepuasan Kerja $\left(\mathrm{X}_{2}\right)$ sama dengan nol. Serta nilai koefisien determinasi dari persamaan regresi linear berganda sebesar 0,137 hal ini menunjukkan bahwa kontribusi variabel komitmen organisasi $\left(\mathrm{X}_{1}\right)$ dan Variabel Kepuasan Kerja $\left(\mathrm{X}_{2}\right)$ pada perubahan OCB (Y) sebesar 13,7 \% sedangkan sisanya $86,3 \%$ dipengaruhi oleh variabel lain diluar dari model analisis.

\section{PENUTUP}

\section{Simpulan}

Berdasarkan hasil penelitian yang didapatkan, maka dapat ditarik kesimpulannya sebagai berikut :

a. Komitmen Organisasi berpengaruh positif tetapi tidak signifikan terhadap Organizational Citizenship Behaviors pegawai di Yayasan Pendidikan Islam di Tanah Papua Cabang Kabupaten Jayawijaya.

b. Kepuasan Kerja berpengaruh positif dan signifikan terhadap Organizational Citizenship Behaviors pegawai di Yayasan Pendidikan Islam di Tanah Papua Cabang Kabupaten Jayawijaya.

c. Komitmen Organisasi dan Kepuasan Kerja secara simultan berpengaruh positif dan signifikan terhadap Organizational Citizenship Behaviors pegawai di Yayasan Pendidikan Islam di Tanah Papua Cabang Kabupaten Jayawijaya.

\section{Saran}

Berdasarkan kesimpulan yang didapatkan, maka peneliti memberikan saran diantaranya diharapkan Pengurus Yayasan agar terus memperhatikan Komitmen Organisasi dari pegawai terutama pada komitmen continuance (berkelanjutan) dan komitmen normative dengan cara memberikan rasa aman bagi seluruh pegawai. Diharapkan pula agar terus meningkatkan kepuasan kerja pegawai dengan cara membuka diri untuk mengetahui keinginan dan kebutuhan pegawai terutama pada kebijakan gaji yang disesuaikan dengan kenaikan harga barang di Kabupaten Jayawijaya. Agar penelitian tentang Faktor - Faktor Organizational Citizenship behaviors dapat lebih meningkat diharapkan melanjutkan dengan variabel - variabel lainnya yang saat ini belum dianalisis diantaranya iklim organisasi, motivasi, budaya organisasi

\section{DAFTAR PUSTAKA}

Arum, D. D., Lina, H., \& Herlina. (2013). Pengaruh Kepuasan Kerja dan Komitmen Organisasi terhadap Organizational Citizenship Behavior. Jurnal Economia, 9(1), 10-17.

Dewi, N. L. P. Y. A., \& Suwandana, I. G. M. (2016). 
Pengaruh Kepuasan Kerja Terhadap Organizational Citizenship Behavior (OCB) Dengan Komitmen Organisasional Sebagai Variabel Mediasi. E-Jur, 5(9), 5643-5670.

Er Hamza, A. N. (2015). Pengaruh Komitmen Organisasi, Kepuasan Kerja dan Budaya Organisasi Terhadap Organizational Citizenship Behavior (OCB) Studi Pada PT Sinar Puspita Abadi Factory Banyuputih, Batang. Jurnal Fakultas Ekonomi Dan Bisnis UDINUS Semarang, 1-22.

Fitriastuti, T. (2013). Pengaruh Kecerdasan Emosional, Komitmen Organisasional dan Organizational Citizenship Behavior Terhadap Kinerja Karyawan. Jurnal Dinamika Manajemen Http://Journal.Unnes.Ac.Id/Nju/Index.Php/Jdm ANALISIS, 4(2), 184-191. https://doi.org/10.1017/CBO9781107415324.004

Hadjali, H. R., \& Salimi, M. (2012). An investigation on the effect of organizational citizenship behaviors ( OCB ) toward customer-orientation: A case of Nursing home. Procedia - Social and Behavioral Sciences, 57, 524-532. https://doi.org/10.1016/j.sbspro.2012.09.1220

Haedar, Saharuddin, \& H, H. (2015). Pengaruh Lingkungan Kerja dan Masa Kerja Terhadap Kepuasan Karyawan pada PT. Hadji Kalla Palopo. Jurnal Manajemen, 02(01), 11-22.

Hamid, R. S., \& Patra, I. K. (2019). PENGANTAR STATISTIKA UNTUK RISET BISNIS DAN EKONOMI Konsep Dasar dan Aplikasi SPSS versi 25. Banten: CV. AA. RIZKY.

Harper, P. J. (2015). Exploring forms of organizational citizenship behaviors ( OCB ): antecedents and outcomes. Journal of Management and Marketing Research, 18(February), 1-16.

Hidayat. (2014). Faktor - Faktor Komitmen Organisasi Serta Pengaruhnya Terhadap Organizational Citizenship Behavior (OCB) ( Studi pada Karyawan PT . Nusa Tama Furniture ). Jurnal $\mathrm{NeO}$-Bis, 8(1), 1-14.

Islam, T., Khan, S. ur R., Ahmad, U. N. U., \& Ahmed, I. (2014). Exploring the Relationship Between POS, OLC, Job Satisfaction and OCB. Procedia Social and Behavioral Sciences, 114, 164-169. https://doi.org/10.1016/j.sbspro.2013.12.678

Majorsy, U. (2007). Kepuasan Kerja, Semangat Kerja dan Komitmen Organisasional Pada Staf Pengajar Universitas Gunadarma. Psikologi, 1(1), 1-32.

Polat, S. (2009). Organizational citizenship behavior (OCB) display levels of the teachers at secondary schools according to the perceptions of the school administrators. Procedia - Social and Behavioral Sciences, $\quad 1(1), \quad 1591-1596$. https://doi.org/10.1016/j.sbspro.2009.01.280
Prabandewi, P. A., \& Indrawati, A. D. (2016). Pengaruh Kepuasan Kerja, Komitmen Organisasi dan Gender Terhadap Organizational Citizenship Behavior PT.BPR PEDUNGAN. E-Jurnal Manajemen Unud, 5(10), 6517-6547.

Prihatsanti, U., \& Dewi, K. S. (2010). Hubungan Antara Iklim Organisasi dan Organizational Citizenship Behavior. Jurnal Psikologi Undip, 7(1), 11-17. https://doi.org/10.14710/jpu.7.1.11-17

Purba, D. E., \& Seniati, A. N. L. (2004). Pengaruh Kepribadian Dan Komitmen Organisasi Terhadap Organizational Citizenzhip Behavior. Makara, Sosial Humaniora, 8(No 3), 105-111.

Puspitawati, N. M. D., \& Riana, I. G. (2014). Pengaruh kepuasan kerja terhadap komitmen organisasional dan kualitas layanan. Jurnal Manajemen Strategi Bisnis Dan Kewirausahaan, 8(No 1), 68-80.

Rini, D. P., Rusdarti, \& Suparjo. (2013). Pengaruh Komitmen Organisasi, Kepuasan Kerja dan Budaya Organisasi Terhadap Organizational Citizenship Behavior (OCB) (Studi pada PT. Plasa Simpanglima Semarang). JURNAL ILMIAH DINAMIKA EKONOMI DAN BISNIS, 1(1), 6988.

Ristiana, M. (2013). Pengaruh Komitmen Organisasi Dan Kepuasan Kerja Terhadap Organizational Citizenship Behavior ( OCB ) Dan Kinerja Karyawan Rumah Sakit Bhayangkara Trijata Denpasar. DIE, Jurnal Ilmu Ekonomi \& Manajemen, 9(1), 57-70.

Sayuti, N. L., \& Sammang, S. (2018). Pengaruh Kepribadian dan Komunikasi Interpersonal Terhadap Komitmen Organisasional Pada Dinas Kesehatan Kota Palopo. Jurnal Manajemen, 4(1), 31-36.

Syahril, N., \& Widyarini, M. N. (2007). Kepribadian, kepemimpinan transformasional, dan perilaku kewargaorganisasian. Jurnal Pskilogi, 1(1), 40 46.

Utama, D. P. P. C., \& Wibawa, I. M. A. (2016). Pengaruh Kepuasan Kerja Terhadap Komitmen Organisasi dan Organizational Citizenship Behavior Pada Karyawan Bali Rani Hotel. EJurnal Manajemen Unud, 5(4), 2511-2543.

Widyanto, R., Lau, J. S., Kartika, E. W., Perhotelan, M., \& Petra, U. K. (2013). Pengaruh Kepuasan Kerja Terhadap Organizational Citizenship behavior (OCB) Melalui Komitmen Organisasional Karyawan Cleaning Servica di ISS Surabaya. Jurnal Hospitality Dan Manajemen Jasa, 1(1), 36-50.

Zeinabadi, H., \& Salehi, K. (2011). Role of procedural justice, trust, job satisfaction, and organizational commitment in organizational citizenship behavior (OCB) of teachers: Proposing a modified 
social exchange model. Procedia - Social and Behavioral Sciences, 29(Iceepsy), 1472-1481. https://doi.org/10.1016/j.sbspro.2011.11.387 